DANIEL P. SULMASY

"DISEASES AND NATURAL KINDS"

\begin{abstract}
David Thomasma called for the development of a medical ethics based squarely on the philosophy of medicine. He recognized, however, that widespread anti-essentialism presented a significant barrier to such an approach. The aim of this article is to introduce a theory that challenges these anti-essentialist objections. The notion of natural kinds presents a modest form of essentialism that can serve as the basis for a foundationalist philosophy of medicine. The notion of a natural kind is neither static nor reductionistic. Disease can be understood as making necessary reference to living natural kinds without invoking the claim that diseases themselves are natural kinds. The idea that natural kinds have a natural disposition to flourish as the kinds of things that they are provides a telos to which to tether the notion of disease - an objective telos that is broader than mere survival and narrower than subjective choice. It is argued that while nosology is descriptive and may have therapeutic implications, disease classification is fundamentally explanatory. Sickness and illness, while referring to the same state of affairs, can be distinguished from disease phenomenologically. Scientific and diagnostic fallibility in making judgments about diseases do not diminish the objectivity of this notion of disease. Diseases are things, not kinds. Injury is a concept parallel to disease that also makes necessary reference to living natural kinds. These ideas provide a new possibility for the development of a philosophy of medicine with implications for medical ethics.
\end{abstract}

\title{
INTRODUCTION
}

Twenty-five years ago, in the pages of this journal, David C. Thomasma and Edmund D. Pellegrino challenged the field by arguing that medical ethics must begin with the philosophy of medicine. ${ }^{1}$ Before his untimely death, Dave let us know that such a comprehensive philosophy of medicine - one that could serve as a foundation for medical ethics - still eluded us. Perhaps, he seemed to suggest, it had only become more difficult to achieve. In 1997, he wrote,

What is needed today is ... a movement from radical pluralism and contentless analysis to moral foundations. In other words, we must move beyond contemporary bioethics to a moral philosophy of medicine. Given the troubled state of philosophy and especially of moral philosophy and ethics, as well as major changes in the 
practice of medicine today, the movement back towards foundations will be difficult indeed. $^{2}$

In this essay, dedicated to David's memory, I would like to set forth a possible new direction for pursuing this challenge. As he noted, such an endeavor amounts to swimming upstream against the currents of contemporary "bioethics." Despite the difficulties, however, it would appear that substantial new work in analytic philosophy might (surprisingly) lead to the sort of foundation for the philosophy of medicine and medical ethics that David sought. The notion of natural kinds has become very important in contemporary Anglo-American philosophy, but scholars have not yet taken seriously how the notion that human beings are a natural kind might have implications for the philosophy of medicine and medical ethics. I will not attempt to lay out all of the implications of this idea in a single essay. Rather, I will attempt to explain the notion of a natural kind, and to outline some of the ways in which this notion might help to illuminate a few fundamental questions about disease and health care. In the long run, a philosophy of medicine based centrally upon the notion of the human as a natural kind might be exactly the sort of foundation for medical ethics that David Thomasma sought.

\section{THE PROBLEM OF ANTI-ESSENTIALISM}

Essences have not been very popular in recent philosophy. Positivists, for instance, complained that they had never seen one. The philosophy of medicine has also largely discarded essentialism as a sort of lingering, outmoded Aristotelian habit of speech, or as Jensen has written, "the child of a static (pre-Darwinian) view of nature."3 Jensen goes on to say that, "A unit of classification is a human construct," and argues that since diseases are evolving entities, they cannot be assigned essences, which are necessarily static. ${ }^{4}$

The idea that all classifications are human constructs is not new. It traces its origins to 13 th century nominalism. But mere nominalism is not radical enough for the 21 st century. For the post-modern bioethicist, medical terms are all socially constructed and thus, little more than disguised attempts to assert power and domination over others. Thus, one group of postmodern feminists has critiqued the research agenda in women's health, writing that the concept to which the word 'woman' refers is " ccrowded with the overdeterminations of 
male supremacy,' and... contaminated with misogyny and sexism."5 They argue further that 'gender' and 'sex' are also tainted with essentialism.

The idea of pure sex difference uninfluenced by social constructions presupposes a mythical time prior to gendering. Since it is impossible to be both inside culture and outside it at the same time, sexual differences are always already informed by gender. Poststructuralist critiques have demonstrated that women's bodies and their experiences are only knowable through the discourses that constitute them, so both sex and gender are socially constructed. ${ }^{6}$

Nonetheless, to advance their own political agenda of claiming power for women and righting past injustices, they advocate a cynical appropriation of the essentialist terms 'woman', 'sex', and 'gender' as tools for their movement.

We argue that a "strategic essentialism," as advanced by Spivak, provides feminists the theoretical ground from which to argue their political agendas. In this formulation, essentialist categories such as woman/women, sex, or gender are used strategically to achieve specific purposes or aims. In Spivak's terms, strategic essentialism is the "strategic use of a positivist essentialism in a scrupulously visible political interest." In this sense, the strategy suits the situation, and the essentialized term (i.e., woman) becomes a mobilizing slogan aimed at specific political ends. ${ }^{7}$

In an academic climate such as this, small wonder that Dave Thomasma thought that the movement back to foundationalism would be difficult. And yet, powerful arguments are emerging in recent analytic philosophy that are making the concept of essentialism not only respectable once again, but even changing the antiessentialist received view.

\section{NATURAL KINDS}

Consider the work of Saul Kripke on identity and necessity. ${ }^{8}$ Kripke has argued that "identity statements are necessary and not contingent." He has used the term "rigid designator" to describe what might in an earlier era have been called an essential characteristic of a thing. A rigid designator is "a term that designates the same object in all possible worlds." He does not imply that the thing must exist, of necessity, in all possible worlds, but rather that if it were to exist in any possible world, the rigid designator would designate it in that world. 
This is not trivial or obscure in its consequences for medical ethics. Every time, for instance, that one requests a substituted judgment, the question is framed as a contrary to fact conditional that posits a possible world that is not our own. A clinician asks the daughter of a comatose patient, "What would your mother, Mrs. Penelope Smith, have wanted in terms of life sustaining treatment if she were able to speak to us today?" Kripke would insist that the Mrs. Penelope Smith to whom we refer in the possible world in which comatose people's thoughts can be understood is not some other person who happens to look like Mrs. Penelope Smith, but is identical with the Mrs. Penelope Smith lying in the bed in the ICU. It is this woman's values we are after.

It is critically important to note that this routine exercise in clinical ethics, the elicitation of a substituted judgment, hailed by purportedly anti-essentialist bioethicists everywhere, is not even conceptually possible unless there is something akin to the essence of Mrs. Penelope Smith. She is rigidly designated by her name.

Baruch Brody's analysis would also support this interpretation, but on more forthrightly essentialist, Aristotelian grounds. ${ }^{9}$ Brody argues that "identity across possible worlds is prior to rigid designation," $" 10$ and that something must already have been picked out as the same in any possible world before it can be designated as such.

Kripke's work on naming, identity, and natural necessity has also been complemented and even extended by David Wiggins' work on natural kinds. ${ }^{11}$ Wiggins has developed the notion of "sortal predicates" by which entities of a certain kind are picked out, identified, and re-identified over time. He has come to the conclusion that the predicate calculus simply cannot account for much of what is (particularly living things) unless it is enriched by the addition of the concept of a sortal predicate. ${ }^{12}$ In other words, one cannot say "Smith is the same man I saw yesterday" without predicating that Smith and the man I saw yesterday belong to the same natural kind (in this case, man). And if this is the case, then Wiggins says, we must embrace at least a "modest" form of essentialism. These essences are not Platonic forms. As Wiggins puts it, essences are not "fancied vacuities parading in the shadow of familiar things as the ultimate explanation of everything that happens in the world. They are the natures whose possession by their owners is the precondition of their owners being divided from rest of reality as anything at all."13

With respect to the philosophy and ethics of medicine, one would think it obvious that at least this sort of modified essentialism would 
be necessary in order to function in the clinical world. But while this might be obvious to clinicians, it has not been obvious to philosophers. How might the concept of natural kinds bridge the gap between the common sense essentialism of clinicians and the philosophy of medicine? Building on the work of Putnam, Wiggins very clearly, if densely, tells what a natural kind entails:

The determination of a natural kind stands or falls with the existence of law-like principles that will collect together the actual extension of the kind around an arbitrary good specimen of it; and these law-like principles will also determine the characteristic development and typical history of members of this extension. ${ }^{14}$

\section{DISEASES AND NATURAL KINDS}

I will argue that one cannot understand human disease unless one understands that human beings are a natural kind. This is not to argue that diseases are natural kinds, ${ }^{15}$ but that the concept of a disease must make necessary reference to a natural kind.

If one is sincerely interested in acquiring knowledge about a subject, rather than beginning with obscure cases proposed as counterarguments in support of all manner of skeptical conclusions, one should begin by studying what is common and paradigmatic. The concept of natural kinds provides a framework for doing so. Taking biology, pathology, plant science, human medicine, and veterinary medicine very seriously seems critical to any contemporary discussion of the general notion of disease. In this light, the following points are worth noting:

(1) A disease is always a disease of (at least one) living natural kind. For example, powdery mildew is a disease that afflicts members of at least one living natural kind - rosemary bushes (Rosmarinus officinalis). But it is not a disease of the human natural kind. Human diseases are diseases of members of the human natural kind.

(2) Diseases can afflict more than one natural kind. Plants other than rosemary, such as grapes and roses, can become diseased with powdery mildew. Dogs and human beings both can be afflicted with myasthenia gravis.

(3) Diseases of one natural kind may be caused by another natural kind - e.g. Erysiphe spp. and Sphaerotheca spp. are among the natural kinds causing powdery mildew. Plasmodium falciparum causes one type of malaria in human beings. But clearly not all diseases are caused by one natural kind invading another. There is no known pathogenic natural kind that causes myasthenia gravis.

The important point is that to understand any of the conditions named above as diseases, one must understand how these conditions 
affect the afflicted individual as the kind of thing that it is. There are law-like principles that determine the characteristic history and typical patterns of development that collect together the actual extension of those individual entities one calls members of the human natural kind. In fact, two arbitrary, good specimens of this natural kind have been picked out, radiologically dissected, and their anatomical features placed on line at the National Library of Medicine in Bethesda, Maryland. And amazingly enough, the average man or woman (or even child), is easily able to tell which entities belong to this natural kind (and their sex), in the absence of technical anatomical knowledge and without reference to a political agenda. One can also readily recognize those deviations from the characteristic development and typical history that render some members of this natural kind defective. So, children born with syndactyly (webbed fingers) are defective members of the human natural kind. They are not members of some other natural kind, say dolphins. To say something is a defective $\mathrm{X}$ implies that one knows what kind of thing an $\mathrm{X}$ is. Without at least this much essentialism, medicine would not even be conceptually possible.

\section{NATURAL KINDS AND NATURAL TELEOLOGY}

Natural kinds have a natural teleology. To say that they have characteristic patterns of development and typical histories implies a teleology. Anthony Lisska has called the properties that determine the pattern of development of a natural kind its "dispositional predicates." 16 The successful unfolding of these dispositions over developmental time - a program and a pattern - allows the individual to flourish as the kind of thing that it is.

Natural kinds have dispositions. This much teleology must be granted.

Uranium undergoes a characteristic pattern of radioactive decay. Various types of stars have dispositional predicates. They develop and change over periods of time that may seem long by human standards, but there is a pattern by which a star's history must unfold temporally if it is to behave as the kind of thing that it is.

Dispositional predicates seem especially characteristic of living natural kinds. In fact, Philippa Foot has written that the word 'good' is an attributive adjective, not a predicative adjective, and cannot be understood apart from an understanding of what kind of thing 
something is. ${ }^{17}$ So, for instance, the word 'good', as used in the phrase, "good roots," cannot be understood unless one knows that it is being attributed to a rosemary bush and not to a rhinoceros. Having deep roots would not be good for a rhinoceros.

Natural kinds have natural tendencies. Much of the scientific enterprise consists of coming better to understand these natural tendencies. This teleology is natural. It does not imply the anthropomorphizing of things or the ascribing of conscious goal-directed activity to them, nor does it imply that there is a deity that directs their development. That natural kinds have law-like principles that determine how they develop and flourish as the kinds of things that they are is simply a fact about the world as we encounter it.

\section{NATURAL KINDS AND EVOLUTION: BIOLOGICAL AND EPISTEMIC}

Natural kinds are not timeless, changeless Platonic entities. The concept of a natural kind is perfectly compatible with biological evolution. That living natural kinds evolve over time is simply one of the law-like generalizations that characterize them. Some will go extinct. Some may change so dramatically that they become a new natural kind. But for human medicine (as well as veterinary medicine and botany), the slow time frame of evolutionary change is just not significant for clinical pathology and practice.

Human understanding of the law-like generalizations that determine the characteristic development and typical history of natural kinds may also change over time. But this does not mean that the kind has changed, merely our understanding of it. This understanding has a mind-to-world direction of fit - i.e. - our understanding must be better fitted to the kind; the kind is not shaped to our understanding of it. ${ }^{18}$ Thus, there is scientific progress in medicine. Humoral theories of disease have been abandoned. Bloodletting has been replaced by plasmaphoresis. But the gene of Mendel and the gene of Watson and Crick are one and the same gene, now understood in greater depth. Genetics is the study of one aspect of the lawlike principles that determine the characteristic development and typical history of living natural kinds. We understand human genetic principles better now than we did 200 years ago. But it is still the same natural kind that is studied and treated by human medicine the human natural kind. 


\section{NATURAL KINDS AND EMERGENT PROPERTIES}

The idea of a natural kind is not reductionistic. The fundamental way that complex systems are understood is through a hierarchical analysis of their structure, recognizing that there is both "top-down" and "bottom-up" causation along the hierarchical levels. ${ }^{19}$ Natural kinds can be understood at multiple hierarchical levels of organization, and lower levels of organization are neither individually nor jointly sufficient to explain higher levels of organization, or even sufficient to ask the questions that would be relevant to the understanding of the kind at that higher level of organization. These properties, those that can only be understood in relation to the hierarchical level of organization to which they belong, are said to be "emergent." That is to say, they "supervene" only at successively higher levels of organization, but cannot be fully explained by lower levels of organization. Thus, physics is insufficient to explain chemistry, chemistry is insufficient to explain biology, biology is insufficient to explain psychology, and psychology is insufficient to explain morality. For example, cell walls contain both quarks and $\mu$-mesons, but quarks and $\mu$-mesons cannot explain what a cell wall is.

This does not preclude the work by which scientists can arrive at partial explanations of various states of affairs of a given natural kind, considered at a given level of organization, by invoking an understanding of one or another state of affairs of lower levels of organization of the kind. Thus, at a chemical level, understanding that a base pair mutation results in the substitution of valine for glycine at the 6th position of the $\beta$ chain of the hemoglobin molecule provides a substantial causal explanation for sickle cell disease. This information is useful and important. It has diagnostic and therapeutic implications. But as an explanation of what sickle cell disease is, it is radically incomplete. One cannot understand this disease without also understanding the biology of Plasmodium falciparum, the ecological concept of inclusive fit, population genetics, patterns of migration, the physiology of blood flow, the existence of capillaries, the biology of pain, and the concept of infarction, none of which can be fully reduced to chemistry. The chemical explanation deepens the biological explanation, but only biology and levels of scientific hierarchy above the biological (so-called "top-down causation") fully explain the biological phenomena.

A moral, rational, living natural kind can be understood, nonreductionistically, at multiple, hierarchically arranged levels of organization at which level-specific properties emerge, featuring both 
top-down and bottom-up causation. For the human natural kind, these might be sketched out as:

Evolutionary Ecology

Sociology, Economics, History

Psychology

Physiology

Anatomy

Molecular Biology and Genetics

Physics

The domain of medicine is primarily the domain of the biology of individual members of the human natural kind - particularly the levels of anatomy, physiology, and psychology. Those law-like principles that determine the characteristic development and typical history of members of this natural kind at these hierarchical levels of scientific understanding are the subject of medicine as an applied science. These are the biological principles of the kind. This is not to say that physics and sociology are irrelevant to medicine - patients can develop cancer because of radon exposure and economic factors may help to explain why a particular patient came to be exposed to radon. There is both top-down and bottom-up causation. But medical science cannot claim to be the complete human science. It must have boundaries if it is to be a field of inquiry distinguished from others. And this is determined by its praxis, with its emphasis on caring for the individual with disturbed biology at the level of experience and function. So, for example, molecular biology matters intensely to medicine because it can explain alterations in anatomy, physiology, and psychology and offer possibilities for corrective intervention. There can be "allied" sciences of medical sociology, medical economics, public health, and medical ethics. There is also a field of medical engineering, applying physics to medical care. But these fields merit the adjective, 'medical' precisely because they can help to explain or can help produce effective interventions in matters of anatomy, physiology, and psychology.

\section{A DEFINITION OF DISEASE}

This much being said, I am now ready to offer a formal definition of disease. 
A disease is a class of states of affairs of individual members of a living natural kind

$\mathbf{X}$, that:

(1) disturbs the internal biological relations (law-like principles) that determine the characteristic development and typical history of members of the kind, $\mathbf{X}$,

(2) in a pattern of disturbance shared with at least one other member of the kind, $\mathbf{X}$.

(3) The aim of this classification must be to provide at least a provisional basis for explaining the causes and/or natural history of a disturbance in the internal biological relations of the affected members of $\mathbf{X}$ (and, if $\mathbf{X}$ is a self-reflective natural kind, can serve as an explanation of the illness of those so affected),

(4) and at least some individuals of whom (or which) this class of states of affairs can be predicated are, by virtue of that state, inhibited from flourishing as Xs.

I must further explicate this fairly dense definition.

A. A disease is not a natural kind. It is a classification of a certain state of affairs that can occur in members of particular living natural kinds.

B. The "biological internal relations (law-like principles)" encompass anatomy, physiology, and psychology. Not all variations in the law-like principles that govern natural kinds at these levels of organization are diseases, but only those variations that also meet the other criteria.

C. There are no diseases that are unique to particular individuals. Individuals may be sick or ill, but until the pattern of disturbance is detected in other members of the kind, it is not a disease. Disease is a scientific concept and concerns more than the individual.

D. The purpose of disease classification (nosology) is, in the first place, explanatory. Even if the disease does not provide a causal explanation for the illness, the purpose of bringing a pattern of disturbance under a particular name is to predict an expected natural history and provide the first step towards explanation. Even if the explanation is not scientific by contemporary standards (e.g., possession by demons or angry ancestors), the classification of a pattern of disturbance in the law-like principles that govern the biological organization of a living natural kind as a disease serves an explanatory function.

E. The hope of medical practice is that better explanatory knowledge of a disease will provide better treatment. The 19th and 20th centuries rewarded medicine handsomely for pursuing explanatory knowledge of diseases. The eventual payoff was better therapy. But the aim of nosology is fundamentally explanatory, not therapeutic. 
F. There can be asymptomatic disease. But if a pattern of disturbance in the law-like biological principles that determine the characteristic development and typical history of a living natural kind is to be called a disease, at least some individuals with the disease must be inhibited from flourishing as the kinds of things that they are. For example, prostate cancer at age 80 may be "incidental" and never interfere with a man's flourishing. But unless prostate cancer interfered with at least some men's flourishing, it would not be called a disease.

G. The telos in this definition is that the individual should flourish as the kind of thing that it is. This is an important difference from Christopher Boorse's specification of the telos in his definition of disease as survival and reproduction. ${ }^{20}$ Survival and reproduction might be sufficient for an amoeba to flourish as the kind of thing that it is. But survival is scarcely enough for a rosemary bush, never mind a human being. A rosemary bush might survive a bout of powdery mildew, live a normal lifespan, and reproduce well. But while infected, it is not flourishing as a rosemary bush. Likewise, a human being with a coronavirus infection has a disease (the common cold). It is almost inconceivable that this could affect her survival or reproduction. But while infected, she fails to flourish as the kind of thing she is.

$\mathrm{H}$. Setting as the telos the flourishing of the individual as the kind of thing that it is also explains why it can be controversial to classify as diseases certain patterns of variation in the law-like biological principles that determine the characteristic development and typical history of a living natural kind. In particular, patterns of human behavior are most susceptible to being controversially called diseases. But this does not undermine the definition of a disease. It is only to say that the task of deciding whether to designate as disease a pattern of variation in the lawlike principles that govern a thing as a member of a kind will have some very clear cases. For example, lung cancer is almost universally thought to interfere with human flourishing. Other cases are much more contestable. For example, homosexuality would not universally be thought to interfere with human flourishing. But this does not imply that the question is a "subjective value judgment." For the human natural kind, such arguments are anthropological, in the philosophical sense of this word. That is to say these are arguments over what kind of a thing a human being is and what constitutes flourishing of the 
individual as a human. The fact that there is epistemological uncertainty about how one can tell whether a human being is flourishing or that there are arguments in philosophical anthropology over what sort of thing a human being is do not imply that what constitutes flourishing as a human being depends solely on human choice and has nothing to do with what a human being is.

I. While human flourishing cannot depend solely upon human choice, this does not mean that human flourishing is uniform. ${ }^{21}$ By virtue of being the kinds of things that they are, human beings are incredibly varied - biologically, psychologically, and socially. Human beings make choices, some of which preclude one good in order to pursue another. There is, therefore, a subject-relativity to the flourishing of human beings that ought not be confused with subjectivity. ${ }^{22}$ Thus, human flourishing includes a certain diversity, and this diversity is objectively good. While the purpose of this essay is not to engage in a discussion of medical ethics, it must be stated that this diversity is not morally unbounded. Human choices ought not detract from the common good (as integrally understood) $)^{23}$ and ought not undermine the basic conditions by which human beings flourish as the kinds of things that they are. ${ }^{24}$

\section{SICKNESS, ILLNESS, SYMPTOMS, SIGNS, AND DIAGNOSIS}

With minor variations, I accept the by-now classical distinction between disease and illness, ${ }^{25}$ and I also accept the distinction between sickness and illness, but with a significant variation on the use of these terms. In sum, I hold that these three words designate three ways of referring to the same state of affairs - individually, socially, and scientifically - corresponding to the terms sickness, illness, and disease, respectively.

Sickness and illness are not the same as disease. ${ }^{26}$ Distinctions between these terms have phenomenological and sociological meaning for human beings. While the first two terms, in particular, are largely synonymous in ordinary language, they can be used as technical terms to stipulate different phenomenological and sociological aspects of the lived experience of diseased human beings. Sickness, as I use the term, is a state of disturbed internal biological relations that appears (from a non-professional perspective) to be inhibiting the 
individual from flourishing as the kind of thing that it is. Individual members of any living natural kind, whether a rosemary bush or a fruit fly, can be said to be sick. Generally, this disturbed state has observable manifestations, but not always. To know that an individual member of a kind is sick, one can observe the pattern of disturbance, and, with at least some knowledge of what it takes for such a kind of thing to flourish, one can make the judgment that the individual is sick. If a crow is walking around in clockwise circles and is not flying, not flapping its wings, not eating, and not cawing, most adult North American observers who know enough about what a crow is and how it typically behaves can make the judgment that the bird is sick. One can also ask for a report (from an individual capable of so reporting) about abnormal sensations or other subjective indications of disturbed biology associated with diminished flourishing. Before one hears a report from the individual, however, one can make one's own judgment and simply ask for confirmation, saying, "You look as if you are sick."

Illness is a socially mediated (but also unscientific) judgment about the exact same state of affairs to which sickness refers. Illness connotes the recognition of a pattern, but is not a judgment that is made with an explanatory intention. An individual manifests a pattern of disturbed internal biological relations and appears not to be flourishing (is sick). Another observer further adduces that this pattern of disturbance is not unique, and that this judgment has been made regarding other members of the kind. Unscientifically, one judges, "This illness is something that has been going around." In a rational, self-reflective, and socially interdependent natural kind such as the human, the individual, subjectively appreciated state that I have called sickness must generally be validated by other member(s) of the kind, thus allowing the ill individual to assume "the sick role." 27

Disease serves as an explanatory designation for the same state of affairs. This individual's sickness, the illness that has been "going around," is explained by judging that the individual suffers from a disease, e.g., influenza. Human disease is therefore also social, but its aim is scientific - an explanation for the observed biological disturbance that does, scientifically, cause at least some individuals, so afflicted, to fail to flourish as the kinds of things that they are.

Symptoms are the sensory signals by which a sensible natural kind is alerted that internal biological relations are askew. When symptoms are sensed by self-reflective individuals, such individuals can use these sense data to judge that they suffer from sickness - feeling 
feverish, nauseated, pruritic, being in pain, etc. Many living natural kinds have such signals. Many of these signals have biological purpose - e.g. - pain may signal that a behavioral response to avoid the offending stimulus is in order. Some are biologically inappropriate, or appropriate in the short-term but not in the long-term. Symptoms are ultimately subjective, even if the cause of the symptoms is not.

Among the members of self-reflective natural kinds, symptoms assume meaning. One author has recently suggested the primary symptom is der Unheimliche (a sense of not being at home in oneself). ${ }^{28}$ An individual sensing symptoms is often initially uncertain of the veracity of a symptom complex or its meaning. This leads the individual to seek validation by others. When this occurs, the patient enters the sick role and concludes, "I am ill."

Disease, by contrast, is a class of patterns of actual disturbance in the internal biological relations of members of a living natural kind that can explain the sickness of individuals of whom the disease can be predicated. Disease can also explain the sickness or illness of afflicted individuals if the natural kind in question is self-reflective and social.

Diagnosis is the art by which specialists determine that an individual's illness can be explained by a particular disease. This art requires recognizing a pattern of disturbance that typifies the state of affairs that defines the particular disease. Diagnosis is an epistemic project. The data are the symptoms (if the individual has the linguistic capacity to report on internal sensations), and signs.

Signs are observable manifestations of disturbances in the internal relations or law-like principles that determine the characteristic development and typical history of sick members of the kind to which the individual belongs. Signs are what others (e.g., doctors and nurses) observe as the effects of illness. Some symptoms cannot be observed and can only be reported, for example, the symptom of seeing yellow halos around lights. Some signs are only observed directly by others, and cannot be experienced subjectively, or even observed of oneself directly, such as an asymptomatic change in the surface of the retina. Often, signs and symptoms will be intrinsically linked. The same phenomenon can have two sides - it can be experienced as a symptom and observed as a sign. For example, a patient may experience the symptom of feeling feverish. If a doctor observes this patient, the doctor will note that the patient has, perhaps among other signs, a fever.

A diagnosis is a disease name that has been judged to be predicable of a state of affairs of a given member of a given natural kind, serving at least as a provisional explanation for the observed pattern 
of disturbance in the internal, kind-typical, biological relations of the individual. A diagnosis is a judgment that the pattern of disturbance in an individual can be classified as belonging to a named disease. Diseases are thus classes of disturbed states of affairs in natural kinds. A diagnosis is a judgment that a certain state of affairs in a particular individual belongs to a certain class.

\section{REASONING ABOUT DISEASES}

Lonergan's distinction between classical and statistical heuristic structures provides an important insight into the ways that diseases are currently understood. ${ }^{29}$ From a scientific point of view, there are two basic ways of understanding phenomena - classically and statistically. In classical science, the data converge upon some formula or understanding, such as $P V=n R T$, or $e=m c^{2}$, or the notion that stars form clusters called galaxies. In statistical science, one appreciates that the phenomenon of interest is itself stochastic, and that one can only understand this phenomenon by coming to know a value such as a mean, from which this inherently non-systematic process cannot systematically deviate. So, for instance, one comes to know that the mean temperature in Paris in July is $18{ }^{\circ} \mathrm{C}$, or that the mean temperature of the background cosmic microwave radiation in space is $2.725^{\circ} \mathrm{K}$.

This distinction is also helpful in understanding medical science, some of which is understood via a classical heuristic structure, and some of which is understood via a statistical heuristic structure. So, for instance, classical physiological laws obtained in medicine, such as the Henderson-Hasselbach equation: $\mathrm{pH}=\mathrm{p} K_{\mathrm{a}}+\log \frac{[\text { conjugate base] }}{\text { [weak acid] }}$. The data about acid-base balance in the human natural kind converge upon this formula. But other processes can only be understood statistically, such as the fact that the ulnar artery is absent in about $3 \%$ of members of the human natural kind.

Diseases likewise are understood both classically and statistically. Pneumococcal pneumonia is an example of a classical disease. The data converge on a particular description of the pattern of disturbance in the internal biological relations afflicting individual members of the human natural kind. This does not mean there will be no variations. In fact, the variation one sees in biology is greater than the variation one sees in physics. There is variation even in physics, and a classical law such as $P V=n R T$ does not describe each measurement of pressure, temperature, molar quantity, and volume, but the for- 
mula upon which multiple such measurements converge. Likewise, the data do converge on a classical description of pneumococcal pneumonia even if it is not true that each and every case of pneumococcal pneumonia is exactly the same.

There are also statistical diseases. Since human diseases are disturbances in the biological law-like properties that govern the typical history and characteristic development of the human natural kind, it is not the mean value or central tendency but variations from the mean that are of concern to medicine. Medicine characterizes some such variations as diseases, to the extent that they also fulfill the other criteria for classifying something as a disease - especially that they inhibit human flourishing. Thus, some statistical variations (such as the absence of an ulnar artery) are not classified as diseases, while others (such as hypertension) are classified as diseases. ${ }^{30}$

The patterns of reasoning by which one makes the judgment that a particular state of affairs in a particular individual belongs to the class defined by a particular disease are multiple and complex deductive, analogical, statistical, pragmatic, and more. A full discussion of diagnostic reasoning is beyond the scope of this essay.

\section{DISEASE, NATURAL KINDS, AND REALISM}

The philosophical literature on diseases has raged on for decades as a pitched battle between realists and anti-realists. The modest essentialism that accompanies the notion of natural kinds provides the basis for a modified form of realism about disease. The view proposed here may provide a solution to the problems posed by previous defenses of disease realism.

Diseases are not primary existents. 'Systemic lupus erythematosis' does not pick out a primary existent, but a class of states of affairs occurring in members of a natural kind(s). Diseases are not natural kinds, but states of affairs. Diseases have no essences.

Saying this does not imply, however, that diseases have no objective basis, or are merely human constructions, or that diseases are merely value judgments. Diseases make necessary reference to natural kinds, and natural kinds admit of at least a modest essentialism. It is essentialism about living natural kinds and their natural dispositions that provides the foundation for realism about diseases. The patterns of disturbance that one classifies as diseases are not arbitrary. It is the pattern of disturbed internal biological relation- 
ships in the natural kind that imposes itself upon the observer; the observer does not impose the pattern upon the affected members of the kind. That is to say, there is a mind-to-world direction of fit - the mind of the observer must conform to the world for the observer's beliefs about disease to be true. The world is the standard by which the observer's beliefs are judged.

Further, many diseases of one natural kind are caused by other natural kinds, and the pattern of disturbed development of a diseased natural kind may reflect the flourishing of the one causing the disease (e.g., in malaria, the illness of a member of the human natural kind is explained by the characteristic development and typical history of Plasmodium falciparum). Thus, the essentialism of two natural kinds may necessarily be invoked in defining some diseases.

\section{Scientific Fallibility}

Arguments are often proposed in (roughly) the following form: It was once thought that $\mathrm{X}$ was a disease. Now, we no longer think that $\mathrm{X}$ is a disease. Therefore diseases are social constructions. ${ }^{31}$

Such arguments seem superficially to be sound, but they are specious. That the medical community can change its beliefs about disease does not imply that diseases are constructed by physicians according to the mores of their era. An alternative interpretation is that the former belief or the present belief or both are wrong.

Medical judgments are fallible. But fallibility does not imply subjectivity. For example, it may turn out that Edwin Hubble was wrong and that the universe is not expanding. But whether Hubble was right or wrong depends upon the universe, not upon the mental states of human beings. In thinking about fallibility in medicine, it is important to distinguish two types of fallible judgment about disease - scientific judgments and diagnostic judgments. Among scientific judgments about diseases, there are two sub-types, both of which are fallible: (1) one may judge incorrectly that what appears to be a pattern of disturbance in the law-like principles governing the internal biological relations of a natural kind constitutes a disease (i.e., one may be wrong in one's scientific judgment that apparent pattern X is a disease) and (2) one may incorrectly formulate a causal explanation for the pattern of disturbance picked out by a disease name (i.e., one may be wrong in one's judgment about the cause of X).

The objective basis for disease classification must be that it makes necessary reference to a natural kind and to disturbances in the 
internal biological relations that inhibit at least some of the affected members of the kind from flourishing as the kinds of things they are. I will argue that, at the end of the day, this is what settles the question of whether a certain observable pattern constitutes disease. Those who offer putative counter-examples, such as the 19th century medical theory that a slave's habitual tendency to try to escape was a disease ("drapetomania"), ${ }^{32}$ do not in any way thereby provide the slightest bit of proof that disease is a "value-judgment." The objective basis for deciding this matter is to ask whether a desire no longer to be a slave is a disturbance in the internal biological relations that inhibits afflicted members of the human natural kind from flourishing as the kinds of things they are. If someone once thought this was true of slaves who wanted to escape, this opinion is simply wrong on both counts. It might be understandable that someone would render such an erroneous opinion given the socioeconomic and historical conditions under which physicians who made such judgments lived. But it is an absolute non-sequitor to conclude that this implies that all diseases are value judgments and that therefore appendicitis is simply a human construct. That judgments are fallible does not mean that they have no objective basis.

Behaviors are particularly susceptible to this sort of error. Even today, whether some behaviors (such as homosexuality or substance abuse) are diseases can be hotly contested by various groups. But again, this does not mean that there is no basis for settling the case. The basis for settling this question is the same: whether there is at least a plausible biological explanation and whether the behavior inhibits human beings from flourishing as the kind of things that they are. That we are not $100 \%$ settled on what constitutes human flourishing does not mean that there is no basis for making such judgments or that there are not thousands of other clear cut cases (such as appendicitis and malaria) where it is obvious that the observed pattern of kind-atypical activity has a biological basis and that this pattern inhibits human flourishing.

Medical science can also be mistaken in its causal explanations about diseases. Malaria (as its name implies) was once attributed to "bad air." Thus, a pattern of disturbance in the law-like characteristics governing the typical development and history of human beings was noted, cases fitting this pattern were carefully classified according to patterns of fever, and each thought to have a particular biological explanation. That explanation made epidemiological sense, and it ultimately fit with the causes of malaria as presently under- 
stood - Anopheles mosquitoes, carriers of the malarial parasites, breed where the air is "bad." Doubtless our future understanding of malaria will deepen further than our understanding today. But the "mal'aria" of medieval Italy and the disease we know today are not two different diseases. They are the same disease, better understood. The fact that we can incorporate previous observations into deeper explanations of the same disease is inconsistent with the assertion that diseases are merely human constructions. Throughout the history of medical science, all we have ever tried to do has been to shape our minds better to fit the world as we encounter it. The fact that we have made mistakes does not mean that disease concepts are merely subjectively or intersubjectively chosen values. The ultimate standard of the truth about malaria and other disease concepts is in the world, not in our heads. That is how we can learn that we have been mistaken in our views about diseases.

Human medical science will establish the criteria for deciding that a particular pattern of disturbance in the biological internal relations of an individual member of the human natural kind falls within the extension of each disease category. One can be mistaken in the criteria that one establishes, because the pattern one is attempting to capture has an objective unity. One discovers that unity; one does not create it. In Lonerganian terminology, a disease is a real thing, even if it is not a natural kind. ${ }^{33}$ One can progress in one's understanding of a thing. For example, the medical community once judged that a diagnosis of the condition known as Lyme Disease required manifestations of an oligoarthritis. As more research was conducted, it was noted that oligoarthritis was one stage in this disease, and that earlier stages had different manifestations such as an erythema migrans rash. The pattern of disturbance in the internal biological relations of the human natural kind to which the disease name 'Lyme Disease' refers did not change. Our scientific understanding of Lyme Disease changed and the diagnostic criteria were adjusted.

\section{Diagnostic Fallibility}

Mistakes are also possible in diagnostic judgments. Whether someone does or does not have a disease is fallible judgment, as all physicians (and medical students) know well. Mistakes are possible at multiple levels. First one must correctly interpret the observable signs and the communicated symptoms (history and physical). Second, one must be knowledgeable about the patterns of signs and symptoms manifested 
by the diseases as they are classified by the medical science of one's era (differential diagnosis). Third, one must be knowledgeable about the appropriate confirmatory tests (diagnostic testing), and sufficiently experienced to use only those that are necessary (diagnostic elegance). Fourth, in the setting of uncertainty, one must avoid the extremes of rashness (making a diagnosis before there are sufficient data) and indecisiveness (deferring judgment when sufficient data are at hand). The art of medicine is the mediation between medical science (concerned with universals) and the individual who must be diagnosed and treated. Diagnosis is a judgment about individuals. As Aristotle has said,

The doctor does not cure 'a man' universally taken, except accidentally, but Callias or Socrates or someone else to whom also the essence of man happens to belong. If, then, someone without the experience has the theory and knows the universal but is ignorant of the individual included under this universal, he will often fail to cure; for it is rather the individual that is curable. (Metaphysics 981a 18-25). ${ }^{34}$

The fact that one can be mistaken in applying the science of one's era in making a judgment about whether a particular disease name can be correctly applied to a particular pattern of disturbance in the internal biological relations of an individual member of the human natural kind does not imply that diseases are value judgments. The logic of diagnosis is intensional. The ultimate standard for whether or not one has correctly applied the disease name (as defined by the science of one's day) to a particular patient is the match between that definition and the state of affairs that actually exists in the affected individual member of the human natural kind who is being diagnosed.

Further, the fact that the standards that are given for defining a disease must, to some extent, be arbitrary and admit of borderline cases, does not mean that diseases are primarily human constructions and value judgments. One must be careful not to confuse the epistemological with the ontological. Definition is an epistemic exercise. Whatever definition one gives will exclude some cases and include others, because this is what a definition does. Giving intensional definitions for ontologically real entities is an inherently fallible enterprise. In a definition of multiple myeloma, for instance, one must arrive at cutoff values, currently set at $>30 \%$ plasma cells in the bone marrow and $>3.5 \mathrm{gms} / \mathrm{dl}$ of an IgG M-protein. ${ }^{35}$ As every experienced clinician knows, some individuals who do not meet these criteria actually have multiple myeloma. However, this only means that the 
reality to which the definition points is prior to the definition. The definition is open to revision, based on its ability to correctly classify cases as belonging to the recurring pattern of disturbance in internal biological relations of the human natural kind that the definition is attempting to capture. There will be mistakes. Some cases will only come to be knowable as the pattern of disturbance in the individual progresses along its own natural history. There will also be borderline cases in which the diagnostic judgment will be difficult. But as Anscombe once remarked (in a quote she attributes to Samuel Johnson), "The fact of twilight does not mean there is no difference between night and day." 36 Borderline cases do not suffice to refute objectivity.

Thus, one must conclude that none of these sources of fallibility in reasoning about diseases provides a philosophical justification for radical skepticism about the realism with which clinicians must undertake the tasks of studying and diagnosing diseases. Diseases are objective perturbations in the reality of the natural kinds of which they can be predicated.

\section{INJURY}

Finally, something must be said about the distinction between disease and injury. I am very sympathetic to the spirit of Boorse's defense against those who criticize his theory for failing to make this distinction. ${ }^{37}$ This distinction is not fundamental to the notion of disease. However, I do think the distinction has some usefulness and should be maintained by the philosophy of medicine. Injury and disease are highly related but distinct concepts. The words are used quite distinctly by both medical laypersons and medical professionals. The sub-specialists who treat diseases (e.g., internists, pediatricians, and family physicians) are different from those who treat injuries (e.g., orthopedists, burn surgeons, and trauma physicians). So, it is probably worthwhile to maintain the distinction. Nonetheless, disease and injury are sufficiently related that the definition of injury is really parallel to that already given for disease. Like disease, injury makes necessary reference to the notion of a living natural kind.

An injury is a state of affairs of an individual member of a living natural kind $\mathbf{X}$, that: (1) disrupts the physical structure or physical integrity that is characteristic of the developmental stage and is typical of the history of members of the kind, $\mathbf{X}$, and (2) this state of affairs inhibits the individual from flourishing as an $\mathbf{X}$. 
This definition of injury is parallel to the definitions of sickness and illness. That is to say, it is a "lay" definition. Unfortunately, there is no ready-made cluster of synonyms that one can use to distinguish the various phenomenological and sociological aspects of injury to parallel the vocabulary of sickness, illness, and disease discussed above. Instead one can therefore call this lay definition, injury sense ${ }_{1}$. In this sense, one can say, as a medical layperson, in parallel to the notion of sickness, "My finger is bleeding," or "I hurt my wrist." Parallel to the sociology I associated with the word, 'illness,' the injured sense ${ }_{1}$ individual may seek intersubjective validation. While the same definition applies, there is therefore a usage we can call injury sense 2 . Thus, my 4-1/2 year old nephew asks, "Do I have a splinter, Uncle Danny?" Or someone says, "You broke your wrist," or "You've burned your hand rather badly."

However, there are many specific injuries that are more like diseases than they are like sickness or illness in that they have been named and categorized by medical science. In the absence of synonyms to use as technical terms, one can call this injury sense ${ }_{3}$. This sense of injury can be defined in a manner more formally parallel to the definition of disease.

A named injury (injury sense ${ }_{3}$ ) is a class of states of affairs of individual members of a living natural kind $\mathbf{X}$, that:

(1) disrupts the physical structure or physical integrity that is characteristic of the developmental stage and is typical of the history of members of the kind, $\mathbf{X}$,

(2) in a pattern of disruption shared with at least one other member of the kind, $\mathbf{X}$.

(3) The aim of this classification must be to provide at least a provisional basis for explaining the causes and/or natural history of this disruption in members of $\mathbf{X}$ (and, if $\mathbf{X}$ is a self-reflective natural kind, can serve as an explanation of the injury sense ${ }_{1}$ of those so affected),

(4) and at least some individuals of whom this class of states of affairs can be predicated are, by virtue of that state, inhibited from flourishing as $\mathbf{X}$ s.

Thus the physician says, "You have a non-displaced Colle's fracture," or "This is a second-degree burn injury involving $2.5 \%$ of the body surface." This is scientific, explanatory vocabulary. The notion of injury sense $_{3}$ is parallel to the notion of disease in every way. While it is a different class of states of affairs of the biology of living natural kinds, injuries ( sense $_{2}$ ), like diseases, can be predicated of any living natural kind. And the concept of injury sense $e_{2}$, like the concept of disease, is objective, even if scientific and diagnostic 
judgments regarding injuries can be just as fallible as those regarding diseases.

\section{CONCLUSION}

The notion of natural kinds can be a powerful starting point for the philosophy of medicine. It provides a philosophically credible basis for objectivity about diseases. The modest essentialism that accompanies the notion of a natural kind meets most objections raised in the literature. It provides a basis for discussion of value in disease discourse, while maintaining that such values are objective and inherent in the dispositional predicates of natural kinds in accordance with a theory of natural goodness and the teleology of a thing flourishing as the kind of thing that it is. It provides a basis for disease realism while avoiding the pitfalls of characterizing diseases as natural kinds themselves. It may provide just the sort of foundation for the philosophy of medicine upon which to develop a medical ethics, following the plan David Thomasma outlined for us but could not carry out before his untimely death.

\section{NOTES}

1 David C. Thomasma and Edmund D. Pellegrino, "Philosophy of Medicine as the Source for Medical Ethics," Metamedicine 2 (1981): 5-11.

2 David C. Thomasma, "Antifoundationalism and the Possibility of a Moral Philosophy of Medicine," Theoretical Medicine 18 (1997): 127-143.

${ }^{3}$ Uffe J. Jensen, "A Critique of Essentialism in Medicine," in Health, Disease, and Causal Explanations in Medicine, eds. Lennart Nordenfelt and B. Ingemar Lindhal (Boston: D. Reidel, 1984), pp. 63-73.

4 Jensen, cited in n. 3, above

5 Janice McCormick, Sheryl Reimer Kirkham, and Virginia Haynes, "Abstracting Women: Essentialism in Women's Health Research," Health Care for Women International 19 (1998): 495-504.

${ }^{6}$ McCormick et al., cited in n. 5, above

${ }^{7}$ McCormick et al., cited in n. 5, above

${ }^{8}$ Saul A. Kripke, "Identity and Necessity," in Identity and Individuation, ed. Milton K. Munitz (New York: New York University Press, 1971), pp. 135-164; Saul A. Kripke, "Naming and Necessity," in Semantics of Natural Language, eds. Gilbert Harman and Donald Davidson (Dordrecht, Netherlands: D. Reidel 1972), pp. 253-355.

9 Baruch Brody, Identity and Essence (Princeton, NJ: Princeton University Press, 1980), pp. 100-134. 
10 Brody, cited in n. 9, above.

11 David Wiggins, Sameness and Substance (Cambridge, Massachusetts: Harvard University Press, 1980).

12 Wiggins, Sameness and Substance, p. 38.

13 Wiggins, Sameness and Substance, pp. 132-133.

${ }^{14}$ Wiggins, Sameness and Substance, p. 169.

15 See the debate about the notion of diseases as natural kinds: Robert D'Amico, "Is Disease a Natural Kind?" Journal of Medicine and Philosophy 20 (1995): 551-569; Lawrie Reznek, "Dis-ease about Kinds: Reply to D'Amico," Journal of Medicine and Philosophy 20 (1995): 571-584. However, the inference both seem to share, that if disease is not a natural kind then it must be a "value judgment," is logically illicit. ${ }^{16}$ Anthony J. Lisska, Aquinas' Theory of Natural Law: An Analytic Reconstruction (Oxford: The Clarendon Press of Oxford University Press, 1996).

17 Philippa Foot, Natural Goodness (Oxford: Clarendon Press of Oxford University Press, 2001).

18 John Searle, Intentionality: An Essay in the Philosophy of Mind (New York: Cambridge University Press, 1983), p. 7.

${ }_{19}$ These ideas draw heavily upon Nancey Murphy and George F.R. Ellis, On the Moral Nature of the Universe (Minneapolis, Minnesota: Fortress Press, 1996), especially pp. 19-87.

${ }^{20}$ Christopher Boorse, "Concepts of Health," in Health Care Ethics: An Introduction, eds. Donald VanDeVeer and Tom Regan (Philadelphia: Temple University Press, 1987), pp. 359-393.

21 Thomas Hurka, Perfectionism (New York: Oxford University Press, 1993).

22 Jukka Varelius, "Autonomy, subject-relativity, and subjective and objective theories of well-being in bioethics," Theoretical Medicine and Bioethics 24 (2003): 363-379.

${ }^{23}$ Daniel P. Sulmasy, "Four basic notions of the common good," St. John's Law Review 75 (2002): 303-310.

${ }^{24}$ Alasdair MacIntyre, Dependent Rational Animals: Why Human Beings Need the Virtues (Chicago: Open Court Press, 1999).

${ }^{25}$ see Christopher Boorse, "On the Distinction Between Disease and Illness." Philosophy and Public Affairs 5 (1975): 49-68; and his later refinements of this distinction in "A Rebuttal on Health," in What is Disease?, eds. James M. Humber and Robert F. Almeder. (Totowa, New Jersey: Humana Press, 1997), pp. 3-134.

${ }^{26}$ While I accept more or less the same distinction, I am using the terms 'illness' and 'sickness' in the opposite manner as has become standard in the philosophy of medicine (see Bjørn Hofman, "On the Triad Disease, Illness and Sickness," Journal of Medicine and Philosophy 27 (2002): 651-673). George Agich says that the standard distinction between illness and sickness is based on ordinary language (see his "Toward a Pragmatic Theory of Disease," in What is Disease? ed. James M. Humber and Robert F. Almeder. 221-246. Totowa, New Jersey: Humana Press, 1997). However, it seems to me that these two words are most often used synonymously in English, and that if there are ordinary language nuances, it appears that they are opposite to what has become standard in the technical language of the philosophy of medicine. Since it is preferable to assign to technical terms the use that is closest to ordinary language, I propose a reversal of the standard use of these terms. I will use 'sickness' to refer to the individual's own subjective experience of disturbed internal 
biological relations, or to an observer's assessment of the disturbed state of an individual. I will use 'illness' to refer to the intersubjectively supported, socially mediated understanding of the same state of affairs. So, we often say that a dog is "sick," but we do not usually say that a dog is "ill." It is also common for a person to say initially to another person, "I feel sick." It is more common to say of another, "She is ill. She has a bug or something." Sickness seems to refer more to an individual and subjective symptoms or observable signs. One is more likely to respond to the question, "How do you feel?" with "I feel sick." It is also a bit more common to say, "Did you miss work because of illness?" than to say, "Did you miss work because of sickness?" The impetus for using sickness as the intersubjective, social term probably comes from Talcott Parsons, who described the sociological legitimation that comes from an intersubjective understanding that someone is ill as "the sick role" (see, "Definitions of Health and Illness in the Light of American Values and Social Structure," in Patients, Physicians, and Illness, ed. E.G. Jaco (New York: Free Press, 1979), pp. 120-144.). Still, I think it best to use our best approximation of the ordinary language uses of these terms. But these are, in any event, technical terms for the concepts that could be given any arbitrary name.

${ }^{27}$ Parsons, cited in n. 21, above.

${ }^{28}$ Fredrik Svenaeus, "Das Unheimliche: Towards a Phenomenology of Illness," Medicine Health Care and Philosophy 3 (2000): 3-16.

29 Bernard J.F. Lonergan, Insight: A Study of Human Understanding (San Francisco, California: Harper and Row, 1978), pp. 33-69.

${ }^{30}$ I am tempted to argue that "statistical" diseases are only epidemiological risk factors for classical ones, but I will not explore this hypothesis further in this essay.

31 For example, this approach is implied by the discussions of homosexuality and masturbation in H. Tristram Engelhardt, The Foundations of Bioethics, 2nd ed. (New York: Oxford University Press, 1986), pp. 189-238. A variation on this fallacious line of argument is the illicit inference that since there are heated arguments in the present about whether certain states such as homosexuality or menopause or aging or infertility are diseases, one must conclude that diseases are socially constructed. This is the tack taken by Arthur L. Caplan in "The 'Unnaturalness' of Aging - Give Me a Reason to Live," in Health, Disease, and Illness, eds. Arthur L. Caplan, James J. McCartney, and Dominic A. Sisti (Washington, DC: Georgetown University Press, 2004), pp. 117-127.

32 Samuel A. Cartwright, "Report on the Diseases and Physical Peculiarities of the Negro Race," in Health, Disease, and Illness: Concepts in Medicine, eds. Arthur L. Caplan, James J. McCartney, and Dominic A. Sisti (Washington, DC: Georgetown University Press, 2004), pp. 28-39.

${ }^{33}$ Lonergan, cited in n.29, above 245-270.

34 Aristotle, Metaphysics, 981a18-25, trans. Hippocrates G. Apostle (Grinnell, Iowa: The Peripatetic Press, 1979), p. 13.

${ }^{35}$ Nikhil C. Munshi, Guido Tricott, and Bart Barlogie, "Plasma Cell Neoplasms," in Principles and Practice of Oncology, 6th ed., eds. Vincent T. DeVita, Samuel Hellman and Steven A. Rosenberg (Philadelphia: Lippincott, Williams, and Wilkins, 2001), p. 2473

36 G.E.M. Anscombe, "War and Murder," in War and Morality, ed. E.A. Wasserman (Belmont, California: Wadsworth, 1970), pp. 42-53. 


\section{REFERENCES}

Agich, George. "Toward a Pragmatic Theory of Disease." In What is Disease?. Edited by James M. Humber and Robert F. Almeder. 221-246. Totowa, New Jersey: Humana Press, 1997.

Anscombe, G.E.M. "War and Murder." In War and Morality. Edited by E.A. Wasserman. 42-53. Belmont, CA: Wadsworth, 1970.

Boorse, Christopher. "Concepts of Health." In Health Care Ethics: An Introduction. Edited by Donald VanDeVeer and Tom Regan. 359-393. Philadelphia: University Press, 1987.

Boorse, Christopher. "On the Distinction Between Disease and Illness." Philosophy and Public Affairs 5 (1975): 49-68.

Boorse, Christopher "A Rebuttal on Health." In What is Disease?. Edited by Humber James M. and Robert F. Almeder. 3-134. Totowa, New Jersey: Humana Press, 1997.

Brody, Baruch. Identity and Essence. Princeton, NJ: Princeton University Press, 1980. Caplan, Arthur L. "The Unnaturalness of Aging - Give Me a Reason to Live." In Health, Disease, and Illness. Edited by Arthur L. Caplan, James J. McCartney and Dominic A. Sisti. 117-127. Washington, DC: Georgetown University Press, 2004.

Cartwright, Samuel A. "Report on the Diseases and Physical Peculiarities of the Negro Race." In Health, Disease, and Illness: Concepts in Medicine. Edited by Arthur L. Caplan, James J. McCartney and Dominic A. Sisti. 28-39. Washington, DC: Georgetown University Press, 2004.

D’Amico, Robert. "Is Disease a Natural Kind?.” Journal of Medicine and Philosophy 20 (1995): 551-569.

Engelhardt, H. Tristram. The Foundations of Bioethics. New York: Oxford University Press, 1986.

Foot, Philippa. Natural Goodness. Oxford: Clarendon Press of Oxford University Press, 2001.

Hofman, Bjørn. "On the Triad Disease, Illness and Sickness." Journal of Medicine and Philosophy 27 (2002): 651-673.

Hurka, Thomas. Perfectionism. New York: Oxford University Press, 1993.

Jensen, Uffe J. "A Critique of Essentialism in Medicine." In Health, Disease, and Causal Explanations in Medicine. Edited by Lennart Nordenfelt and B. Ingemar Lindhal. 63-73. Boston: D. Reidel, 1984.

Kripke, Saul A. "Identity and Necessity." In Identity and Individuation. Edited by Milton K. Munitz. 135-164. New York: New York University Press, 1971.

Kripke, Saul A. "Naming and Necessity." In Semantics of Natural Language. Edited by Gilbert Harman and Donald Davidson. 253-355. Dordrecht, Netherlands: D. Reidel, 1972.

Lisska, Anthony J. Aquinas' Theory of Natural Law: An Analytic Reconstruction. Oxford: The Clarendon Press of Oxford University Press, 1996.

Lonergan, Bernard J.F. Insight: A Study of Human Understanding. San Francisco, California: Harper and Row, 1978.

MacIntyre, Alasdair. Dependent Rational Animals: Why Human Beings Need the Virtues. Chicago: Open Court Press, 1999. 
McCormick, Janice, Sheryl Reimer Kirkham, and Virginia Haynes. "Abstracting Women: Essentialism in Womens Health Research'." Health Care for Women International 19 (1998): 495-504.

Munshi, Nikhil C., Guido Tricott and Bart Barlogie. "Plasma Cell Neoplasms." In Principles and Practice of Oncology. Edited by Vincent T. DeVita, Samuel Hellman and Steven A. Rosenberg. (6th ed. Philadelphia: Lippincott Williams and Wilkins, 2001.

Murphy, Nancey, and George F.R. Ellis. On the Moral Nature of the Universe Minneapolis. Minnesota: Fortress Press, 1996.

Parsons, Talcott. "Definitions of Health and Illness in the Light of American Values and Social Structure." In Patients, Physicians, and Illness. Edited by E.G. Jaco. 120-144. New York: Free Press, 1979.

Reznek, Lawrie. "Dis-ease about Kinds: Reply to DAmico'." Journal of Medicine and Philosophy 20 (1995): 571-584.

Searle, John. Intentionality: An Essay in the Philosophy of Mind. New York: Cambridge University Press, 1983.

Sulmasy Daniel, P. "Four Basic Notions of the Common Good." St. John's Law Review 75 (2002): 303-310.

Svenaeus, Fredrik. "Das Unheimliche: Towards a Phenomenology of Illness." Medicine Health Care and Philosophy 3 (2000): 3-16.

Thomasma, David C., and Edmund D. Pellegrino. "Philosophy of Medicine as the Source for Medical Ethics." Metamedicine 2 (1981): 5-11.

Thomasma, David C. "Antifoundationalism and the Possibility of a Moral Philosophy of Medicine." Theoretical Medicine 18 (1997): 127-143.

Varelius, Jukka. "Autonomy, Subject-relativity, and Subjective and Objective Theories of Well-being in Bioethics." Theoretical Medicine and Bioethics 24 (2003): 363-379.

Wiggins, David. Sameness and Substance. Cambridge, Massachusetts: Harvard University Press, 1980.

The Bioethics Institute of New York Medical College

Sisters of Charity Chair in Ethics

The John J. Conley Department of Ethics

St. Vincent's Hospital - Manhattan

$153 \mathrm{~W}$. 11th Street

New York, NY 10011

U.S.A.

E-mail: daniel_sulmasy@nymc.edu 